\title{
Nanoscale Quantification of Moisture Susceptibility of Paving Asphalts
}

\author{
Sumon Roy ${ }^{1}$ and Zahid Hossain ${ }^{2, *}$ \\ ${ }^{1}$ College of Engineering, Arkansas State University, 504 University Loop, ABI-233W, State University, Jonesboro, AR 72467, USA \\ ${ }^{2}$ College of Engineering, Arkansas State University, PO Box 1740, LSW\#246, State University, Jonesboro, AR 72467, USA
}

\begin{abstract}
Moisture-induced damage due to stripping is one of the major concerns to the highway agencies in recent years. In this study, nanoscopic investigations were carried out to examine the effects of moisture in asphalt binders. An Atomic Force Microscope (AFM) was used to estimate the asphalt binder's modulus and adhesion values, which were believed to be indicators of binder's resistance to moisture damage. To this end, two Performance Grade (PG) binders and their modified counterparts using polyphosphoric acid (PPA), styrene-butadiene-styrene (SBS), and SBS plus PPA were tested in this study. Test results show significant reductions of adhesion and modulus values after water immersion of the asphalt binders. AFM data also reveals that SBS-modified binders exhibit better moisture resistance compared to the base binder. Findings of this study are expected to help transportation professionals to achieve a better understanding of moisture damage of asphalt binders at a molecular level and their suitability in pavements.
\end{abstract}

\section{Introduction}

Moisture damage is one of the distresses that prematurely deteriorates asphalt pavements. In asphalt mixtures, moisture damage can be defined as the loss of strength or stiffness due to the mechanical loading in the presence of moisture, and this phenomenon is also known as stripping [1]. This phenomenon may occur due to the penetration of water into the asphalt mixtures that degrades their mechanical properties [2]. Previous studies also concluded that resistance against moisture damage of asphalt mixtures depends on the adhesive bond strength of the asphalt binder-aggregate system in dry and wet conditions $[3,4]$.

Stripping related moisture damage plays a major role in inducing other types of pavement distresses such as rutting, fatigue cracking, pumping, raveling, and potholes [1,2]. It has been also found that moisture can accelerate damage in asphalt pavements as a combined effect of other types of distress [5]. However, the mechanism pertinent to moisture damage in asphalt concrete is complex, and it may cause due to the adhesive failure (failure of the bond between the asphalt binder and the aggregate), cohesive failure (failure within binder itself), or a combination of adhesive and cohesive failures $[6,7]$. Although several studies have been conducted to identify the root causes of moisture damage in asphalt mixtures and emphasized the necessity of a good understanding of moisture damage at the nanoscale level. Moreover, current laboratory test methods such as Tensile Strength Ratio, Immersion Marshall, and Hamburg Wheel Tracking are empirical in nature. These macro-level tests focus only on the overall strength of a specimen without providing any result that describes the moisture damage phenomenon in the asphalt mixtures [2]. As a result, it is necessary to develop an effective and advanced tool to investigate and quantify the moisture susceptibility of asphalt materials at the atomic level.

In recent years, several researchers studied the qualitative characterization of the microscopic properties of the asphalt binders [8-10]. Moreover, the AFM technology was used to investigate the surface morphology as well as the micromechanical properties such as DMT (Derjaguin, Muller, and Toropov) modulus, adhesion, deformation, and energy dissipation of the asphalt binders [11-16]. These researchers described three distinct phases namely, dispersed phase (Catana), interstitial phase (Peri-phase), and matrix (Para-phase) to characterize the morphological clusters, which were also used in this study. In recent years, the moisture damage of asphalt binder and mixture samples was evaluated by using the AFM technology by some other researchers [2, 17-19].

This research aims at estimating the moisture damage of asphalt materials based on adhesion and modulus values obtained through the AFM tests methods. The effects of moisture on morphological and nanoscopic properties of asphalt binders were evaluated using the Peak-Force Quantitative Nanomechanical Mapping $\left(\mathrm{PFQNM}^{\mathrm{TM}}\right)$ method of a Bruker Dimension Icon AFM system. The major objectives of this study are to: i) develop a simple procedure of AFM sample preparation and tests, ii) characterize morphological and mechanical properties of the asphalt binders at the molecular-level, iii) establish the pertinent correlations among the surface

\footnotetext{
* Corresponding author: mhossain $@$ astate.edu
} 
roughness, adhesion and modulus values, iv) measure the moisture susceptibility of asphalt binders based on the adhesion and modulus values, and v) find the suitable binders for the construction of asphalt pavements.

\section{Materials and methodologies}

\subsection{Materials}

Soft Performance grade (PG) binders from two different sources (i.e., Source 1 and Source 2 labeled as S1 and $\mathrm{S} 2$, respectively) were evaluated in the laboratory. Two types of hard binders (PG 70-22 and PG 76-22) were also investigated in this study, and the modifications were done blending Polyphosphoric Acid (PPA), Styrene-Butadiene-Styrene (SBS), or a combination of PPA and SBS. These PG binders were chosen in this study because they are widely used in Arkansas. At $135^{\circ} \mathrm{C}$, the rotational viscosity values of PG 64-22, PPAmodified PG 70-22, SBS-modified PG 70-22 and PPA plus SBS modified PG 76-22 binders from S1 were 504, 704, 1271, and $1929 \mathrm{mPa} . \mathrm{s}$, respectively. The corresponding viscosities of binders from S2 were 445, 645,1271 , and $1767 \mathrm{mPa} . \mathrm{s}$, respectively. To observe the moisture effects, two sets (dry and wet-conditioned) of specimens of binder were prepared for the AFM tests.

\subsection{AFM sample preparation}

In this study, the heat cast approach (HCA) was followed to prepare the asphalt test samples as it facilitated to obtain a smooth natural surface of the asphalt binder. Multiple researchers [e.g., 16, 20) have followed this method in their corresponding AFM studies. In the HCA, a small amount of asphalt binder is placed on a 2 in $\mathrm{x} 3$ in $(50 \mathrm{~mm} \times 75 \mathrm{~mm})$ glass plate, which is then placed in an oven at $160{ }^{\circ} \mathrm{C}$ for about 15 minutes. Generally, a uniform and smooth surface of the asphalt binder is developed on the glass plate during this time of heating, as shown in Figure 1. The heating time is extended up to 20 minutes for hard binders. One set of the heat cast samples was stored in a humidity-controlled desiccator and tested after three days. These specimens were called "Dry."

For preparing the "Wet" specimens, another set of heat cast samples was stored in the desiccator and was removed after an hour of curing time in air assuming that microstructures of the specimens were stabilized. Later, following steps were followed to make the "Wet" conditioned samples: (i) air-cured specimens were placed in aluminum cans, which were filled with deionized water with a minimum of linch $(25 \mathrm{~mm})$ depth of water above the specimens; (ii) aluminum cans containing the submerged specimens were placed in a vacuum container; (iii) a vacuum of $20-25$ in. $\mathrm{Hg}$ partial pressure (67-84 $\mathrm{kPa}$ absolute pressure) was applied for 10 minutes using a vacuum oven at $104{ }^{\circ} \mathrm{F}\left(40{ }^{\circ} \mathrm{C}\right)$; (iv) After the end of the vacuum cycle, the degassed specimens were left submerged in water for a rest period of 10 minutes; ( $\mathrm{v}$ ) each specimen was then placed in a zip-lock bag, in which $10 \mathrm{ml}$ deionized water was added; (vi) afterwards, the specimens were placed in a freezer at $68{ }^{\circ} \mathrm{F} \quad\left(-20^{\circ} \mathrm{C}\right)$ for $24 \pm 1$ hours, (vii) after 24 hours of freezing, the specimens were removed from the freezer, and placed in a water bath for another $24 \pm 1$ hours at $140 \pm 0.5^{\circ} \mathrm{F}\left(60 \pm 1{ }^{\circ} \mathrm{C}\right)$; (viii) later, the specimens were placed in a water bath for another 2 hours \pm 10 minutes at $77 \pm 1{ }^{\circ} \mathrm{F}\left(25 \pm 0.5^{\circ} \mathrm{C}\right.$ maintaining a water depth of 1 in. above the specimens, (ix) the specimens were then removed from the water bath and the excess water was dabbed off from the surface of the specimens using paper towels; (x) the specimens were then placed in the oven for 16 hours at $77 \pm 2{ }^{\circ} \mathrm{F}\left(25 \pm 1{ }^{\circ} \mathrm{C}\right)$ to ensure the absence of water on the surface of the asphalt binders. The prepared "dry" specimens were then tested.

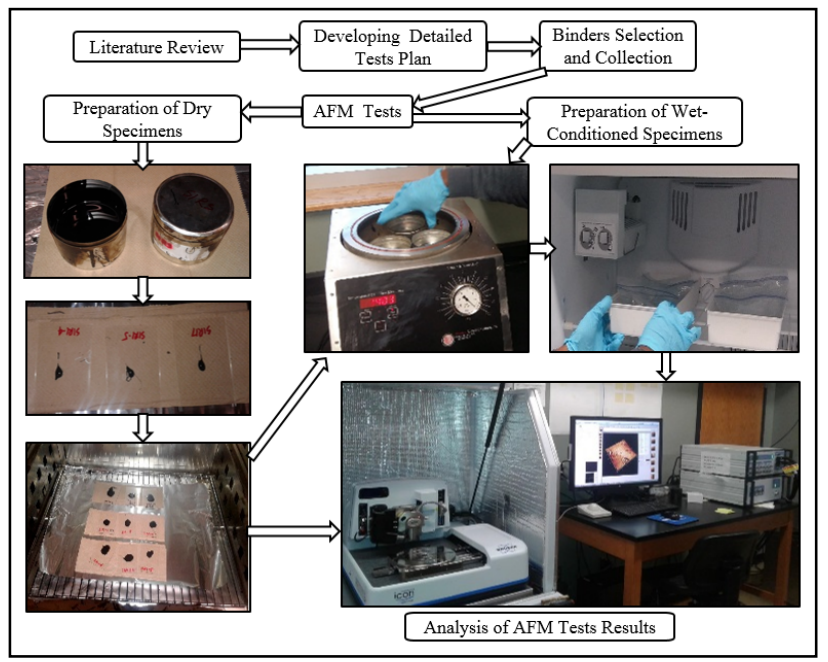

Fig. 1. Major sample preparation steps followed in the study.

\subsection{Laboratory tests}

Prepared specimens were tested by following the Peak Force Quantitative Nanomechanical Mapping (PFQNM ${ }^{\mathrm{TM}}$ ) mode of a Bruker manufactured AFM (Dimension Icon) at $25^{\circ} \mathrm{C}$. Figure 2 shows the working principle of the PFQNM ${ }^{\mathrm{TM}}$ mode. In this study, the following scan parameters were used: scan size of $10 \mu \mathrm{m}$ x $10 \mu \mathrm{m}$, a scan rate of $0.500 \mathrm{~Hz}$, samples/lines of 512 . For each test condition, three replicates were tested, and the average values were taken to compare the test results. After completing the AFM scans, surface morphology and mechanical properties of asphalt binder were analyzed using the NanoScope Analysis 1.5 software.

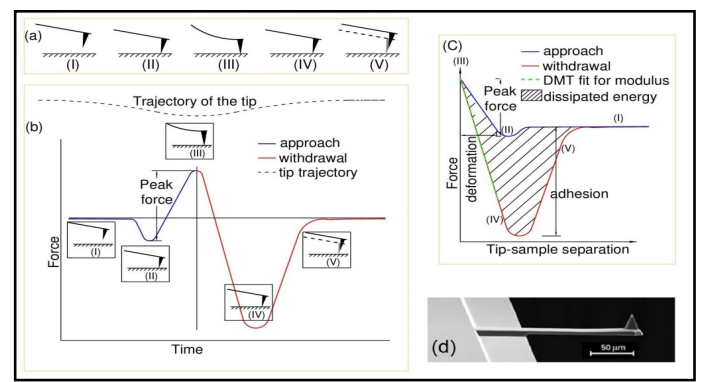

Fig. 2. Working principles of the PFQNM ${ }^{\mathrm{TM}}$ mode: (a) traversing cycle of AFM tip, (b) Peakforce tapping with tip trajectory, (c) force-distance curve, and (d) a typical probe. 


\section{Results and discussions}

\subsection{Effects of moisture on morphology}

Morphological images showed three distinct phases: Dispersed (Catena), Interstitial (Peri), and Matrix (Perpetua). In most of the asphalt binders, the "bee" structures were found to be changed significantly in quantity, size, and shape. They decreased in numbers and sometimes dispersed after the wet conditioning of the specimens. The changes of microstructures on asphalt binders' sample surface may have occurred due to the interactions between water and chemical components of asphalt binder. It was observed that the overall average surface roughness values were reduced over $50 \%$ for SBS-modified binders from both sources. For instance, the SBS-modified binder from S2 showed a reduction in roughness from $4.9 \mathrm{~nm}$ to $2.11 \mathrm{~nm}$. It could be due to the melting of microcrystalline wax and other components in the "bee" structures. Figure 3 shows typical surface morphology maps of a base binder. However, an opposite phenomenon was noticed in the case of control and PPA-modified binders from S2 where a smaller increment was observed after the wet conditioning of the specimens. While surface roughness is not believed to be a direct metric of moisture damage, it is an indicator of degradation of the microstructures of binder samples.
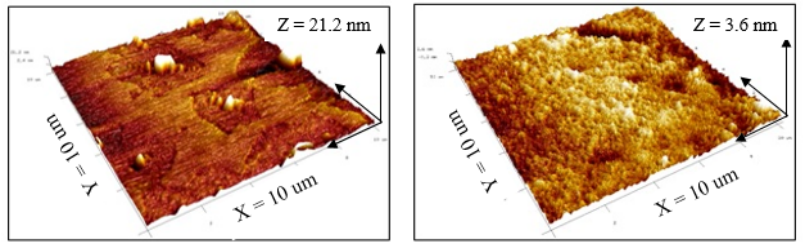

Fig. 3. 3D morphology of PG 64-22 samples from $\mathrm{S} 1$ : dry (left) and wet right).

\subsection{Effects of moisture on adhesion force values}

The AFM test results reveal significant changes in adhesion values due to the action of water, as shown in Figures 4 and 5. Table 1 represents a comparison of the average adhesion values of tested binder samples. It was found that the average adhesion values were reduced in all S1 binders due to the action of water. Among all binders from S1, PG 76-22 binder, which was modified with PPA and SBS, had the lowest reduction (from 31 $\mathrm{nN}$ to $7 \mathrm{nN}$ ) of adhesion force. Such observation is agreement with hard binders having high viscosity and stiffness; a binder having higher viscosity possesses higher bond strength. A similar decreasing trend was also observed in the case of S2 binders although SBSmodified binders (PG 70-22) showed a lower reduction of adhesion (from $13 \mathrm{nN}$ to $11.50 \mathrm{nN}$ ). Such reductions may have happened due to the presence of moisture that has eroded the asphalt binder samples. The effects of moisture were also observed on the three distinct phases of the asphalt binders, as shown in Table 1. It is well known that a high adhesion value of an asphalt binder is an indicator of high resistance against moisture damage. Based on the AFM tests results, it can be concluded that SBS-modified binders from both sources (S1 and S2) showed better resistance to moisture damage.

\subsection{Effects of moisture on modulus values}

AFM test results revealed that DMT moduli were affected by the water action, as shown in Figure 5. The effects of moisture on the dispersed, interstitial, and matrix phases are summarized in Table 2. All S1 binders had lower modulus values in the wet conditioned specimens compared to S2 binders. It can be noted that asphalt binder samples are partly eroded due to the effects of moisture under the wet condition, which may have resulted in lower modulus values in the wet samples compared to the corresponding dry samples [17]. From Table 2, it is also seen that the modulus value reduced (from $963 \mathrm{MPa}$ to $491 \mathrm{MPa}$ ) only for PPAmodified binder of $\mathrm{S} 2$. One of the major findings from AFM tests results is that PG 64-22 binder had higher modulus values (from $43 \mathrm{MPa}$ to $175 \mathrm{MPa}$ ), whereas PPA-and SBS-modified binder had minimal effect (from $173 \mathrm{MPa}$ to $189 \mathrm{MPa}$ ) among all S2 binders. Thus, it can be said that binders modified with PPA and SBS had better moisture resistance than all other asphalt binders tested in this study.
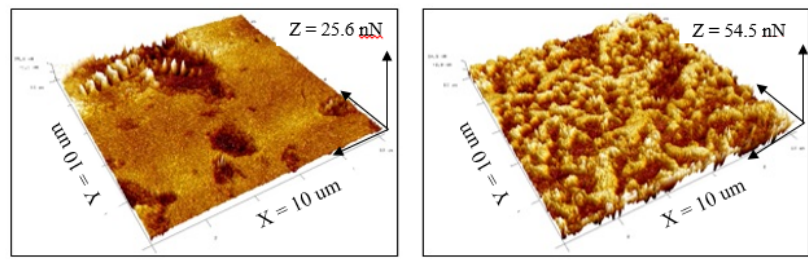

Fig. 4. 3D adhesion maps PG 70-22 (SBS-modified) of S2: dry (left) and wet (right).
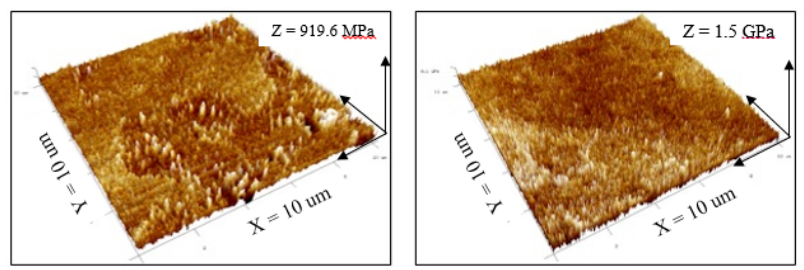

Fig. 5. 3D maps of modulus of PG 70-22 (SBS) from S1: dry (left) and wet-(right).

\section{Conclusions}

An atomic force microscope (AFM) was used to evaluate morphology and mechanistic properties (modulus and adhesion) of asphalt binders. Three commonly used binders (PG 64-22, PG 70-22, and PG 76-22) were investigated in the laboratory. The base binders (PG 6422) used in this study originated from two different crude sources. The hard binders (PG 70-22 and PG 7622) were prepared by using PPA, SBS, or a combination of PPA and SBS. Based on the findings of this study, it 
can be concluded that an AFM can be used as a viable tool for examining the molecular-level properties of asphalt binders. The AFM-based maps helped to visualization of the surface topography of the asphalt binders and their nanoscopic properties, and the microstructures of asphalt binders appeared to disintegrate due to the intrusion of water. Based on the AFM tests results, SBS or PPA plus SBS-modified PG 70-22 and PG 76-22 binders were found to have better resistance to moisture damage than the other tested binders.

Table 1. Summary of adhesion force (nN) using AFM.

\begin{tabular}{|c|c|c|c|c|c|c|c|}
\hline \multirow{2}{*}{ Binders } & \multirow{2}{*}{$\begin{array}{c}\text { Sample } \\
\text { Condition }\end{array}$} & $\begin{array}{c}\text { Average } \\
\text { Value }\end{array}$ & $\begin{array}{c}\text { Dispersed and } \\
\text { Interstitial phase }\end{array}$ & Matrix Phase & $\begin{array}{c}\text { Average } \\
\text { Value }\end{array}$ & $\begin{array}{c}\text { Dispersed and } \\
\text { Interstitial phase }\end{array}$ & $\begin{array}{c}\text { Matrix } \\
\text { Phase }\end{array}$ \\
\cline { 3 - 8 } & Dry & 84.67 & $18-172$ & $13-94$ & 4.61 & $2.12-15.7$ & $1.33-4.73$ \\
\hline \multirow{2}{*}{ PG 64-22 } & Wet & 20.16 & $4.29-51.8$ & $2.1-19.4$ & 10.19 & $2.69-28.6$ & $2.22-10$ \\
\hline \multirow{2}{*}{ PG 70-22 (PPA) } & Dry & 113.33 & $50.2-199$ & $12.1-125$ & 220.67 & $160-278$ & $113-209$ \\
\cline { 2 - 8 } & Wet & 53.53 & $17.7-112$ & $7.46-42.2$ & 130.33 & $73.5-190$ & $33.5-122$ \\
\hline \multirow{2}{*}{ PG 70-22 (SBS) } & Dry & 16.10 & $7.45-24.00$ & $2.82-14.5$ & 12.67 & $2.84-16.2$ & $1.46-8.11$ \\
\cline { 2 - 8 } & Wet & 8.55 & $3.06-10.8$ & $1.67-4.55$ & 11.48 & $3.18-19.7$ & $1.67-7.93$ \\
\hline \multirow{2}{*}{$\begin{array}{c}\text { PG 76-22 } \\
\text { (SBS+PPA) }\end{array}$} & Dry & 30.67 & $16.9-79$ & $4.24-14.3$ & 24.33 & $12.2-38.5$ & $2.86-10.5$ \\
\cline { 2 - 8 } & Wet & 6.95 & $2.36-19.7$ & $1.65-8.65$ & 32.83 & $14.2-84.4$ & $4.96-36.3$ \\
\hline
\end{tabular}

Table 2. Summary of DMT modulus (MPa) values using AFM.

\begin{tabular}{|c|c|c|c|c|c|c|c|}
\hline \multirow[b]{2}{*}{ Binders } & \multirow{2}{*}{$\begin{array}{l}\text { Sample } \\
\text { Condition }\end{array}$} & \multicolumn{3}{|c|}{ Source 1} & \multicolumn{3}{|c|}{ Source 2} \\
\hline & & $\begin{array}{l}\text { Average } \\
\text { Value }\end{array}$ & $\begin{array}{c}\text { Dispersed and } \\
\text { Interstitial phase }\end{array}$ & $\begin{array}{l}\text { Matrix } \\
\text { Phase }\end{array}$ & $\begin{array}{l}\text { Average } \\
\text { Value }\end{array}$ & $\begin{array}{l}\text { Dispersed and } \\
\text { Interstitial phase }\end{array}$ & $\begin{array}{l}\text { Matrix } \\
\text { Phase }\end{array}$ \\
\hline \multirow{2}{*}{ PG 64-22 } & Dry & 536.33 & $250-842$ & $78.9-324$ & 43.30 & $30-114$ & $25.8-50.7$ \\
\hline & Wet & 271.73 & $55.6-630$ & $53.1-339$ & 174.95 & $42.9-345$ & $39.6-225$ \\
\hline \multirow{2}{*}{$\begin{array}{l}\text { PG 70-22 } \\
\text { (PPA) }\end{array}$} & Dry & 462.00 & $120-1334$ & $55.7-278$ & 962.67 & $747-1173$ & $444-965$ \\
\hline & Wet & 198.33 & $69.5-546$ & $56.9-122$ & 490.67 & $195-814$ & $74.2-494$ \\
\hline \multirow{2}{*}{$\begin{array}{l}\text { PG 70-22 } \\
\text { (SBS) }\end{array}$} & Dry & 489.67 & $188-2028$ & $128-723$ & 590.67 & 264-1085 & $244-473$ \\
\hline & Wet & 306.27 & $64.7-532$ & $44.3-353$ & 652.33 & $303-2005$ & $231-563$ \\
\hline \multirow{2}{*}{$\begin{array}{c}\text { PG 76-22 } \\
\text { (SBS+PPA) }\end{array}$} & Dry & 141.63 & $35.7-342$ & $19.7-132$ & 173.33 & $111-359$ & $62.1-130$ \\
\hline & Wet & 75.93 & $52.7-133$ & $45.5-81$ & 189.00 & $95.1-406$ & $63.7-197$ \\
\hline
\end{tabular}

The authors gratefully acknowledge the financial support of TranSET to conduct this study. The authors are also thankful to ArDOT, Paragon Technical Services Inc. and other suppliers for providing test materials and technical support for this study.

\section{References}

1. Moraes, R., Velasquez, R., and Bahia, H.U. (2011). Measuring the Effect of Moisture on AsphaltAggregate Bond with the Bitumen Bond Strength Test. Transportation Research Record: Journal of the Transportation Research Board, 2209(1), 70-81.

2. Yao, Z., Zhu, H., Gong, M., Yang, J., Xu, G., and Zhong, Y. (2017). Characterization of asphalt materials' moisture susceptibility using multiple methods. Cons. \& Bld. Mat, 155(30), 286-295.

3. Bhasin, A., Howson J.E., Masad, E., Little, D., and Lytton, R.L. (2007). Effect of modification processes on bond energy of asphalt binders. Transportation Research Record, 1988, 29-37.

4. Masad E., Zollinger C., Bulut R., Little D.N., and Lytton R.L. (2006). Characterization of HMA moisture damage using surface energy and fracture properties. Asphalt Paving Technology: Association of Asphalt Paving Technologists, 75, 713-48.
5. Cho, D-W., Kim, K. (2010). The Mechanisms of Moisture Damage in Asphalt Pavement by Applying Chemistry Aspects. In KSCE Journal of Civil Engineering, 14(3), 333-342.

6. Little, D.N. and Jones, D.R. (2003). Chemical and Mechanical Processes of Moisture Damage in HotMix Asphalt Pavements. Topic 2, National Seminar on Moisture Sensitivity of Asphalt Pavements, TRB Miscellaneous Report, ISBN 0-309-09450-X, 37-70.

7. Santucci, L. (2010). Minimizing Moisture Damage in Asphalt Pavements. Pavement Technology Update, University of California Pavement Research Center, 2(2), 1-12.

8. Hung, A.M. \& Fini, E.H. (2015). AFM study of asphalt binder bee structures. RSC Adv., 5(117), 96972-96982.

9. Pauli, A.T., Branthaver, J.F., Robertson, R.E., and Grimes, W. (2001). Atomic force microscopy investigation of SHRP asphalts. ACS, Petroleum Preprints, 46(2), 110-114.

10. Schmets, A., Kringos, N.A., Pauli, T., Redelius, P., and Scarpas, T. (2010). On the existence of waxinduced phase separation in bitumen. Int. J. of Pavement Eng, 11(6), 555-563.

11. Masson, J.F., Leblond, V., and Margeson, J. (2006). Bitumen morphologies by phase-detection atomic 
force microscopy. Journal of Microscopy, 221(1), 17-29.

12. Dourado, E.R., Simao, R.A., and Leite, L.F.M. (2012). Mechanical properties of asphalt binders evaluated by atomic force microscopy. Journal of Microscopy, 245(2), 119-128.

13. Fischer, H., Stadler, H., and Erina, N. (2013). Quantitative temperature-depending mapping of mechanical properties of bitumen at the nanoscale using the AFM operated with PeakForce Tapping TM mode. Journal of Microscopy, 250(3), 210-217.

14. Nahar, S.N., Schmets, A.J.M., Schitter, G., and Scarpas, A. (2014). Quantitative nanomechanical property mapping of bitumen micro-phases by peakforce atomic force microscopy. Presented at 12th ISAP Conference on 30 Asphalt Pavements, Raleigh, N.C.

15. Rashid, A.F., and Hossain, Z. (2016). Morphological and nanomechanical analyses of ground tire rubber-modified asphalts. Innovative Infrastructure Solutions, 1(1), 36.

16. Rashid, F., Hossain, Z., \& Bhasin, A. (2017). Nanomechanistic properties of reclaimed asphalt pavement modified asphalt binders using an atomic force microscope. Int. J. of Pav. Eng., 1-9.

17. Tarefder, R.A. and Arifuzzaman, M. (2011). A study of moisture damage in plastomeric polymer modified asphalt binder using functionalized AFM tips. Sys., Cyb, \& Inf., 9(5), 1-12.

18. Das, P.K., Kringos, N., Wallqvist, V., and Birgisson, B. (2013). Micromechanical investigation of phase separation in bitumen by combining atomic force microscopy with differential scanning calorimetry results. Road Materials and Pavement Design, 14(2), 25-37.

19. Yu, X., Burnham, N.A., Mallick, R.B., \& Tao, M. (2013). A systematic AFM-based method to measure adhesion differences between micron-sized domains in asphalt binders. Fuel, 113(9), 443-447.

20. Arifuzzaman, M., Islam, M.S., \& Hossain, M.I. (2017). Moisture damage evaluation in SBS and lime modified asphalt using AFM and artificial intelligence. Neu. Com. \& App., 28(125), 1-10. 